\title{
Erosive Pustular Dermatosis: A Manifestation of Immunosenescence? A Report of 8 Cases
}

\author{
Thusanth Thuraisingam ${ }^{a}$ Paradi Mirmirani $^{b-d}$ \\ ${ }^{a}$ Division of Dermatology, McGill University, Montreal, QC, Canada; ${ }^{\text {T}}$ The Permanente Medical Group, Vallejo, CA, \\ ${ }^{c}$ Case Western Reserve University, Cleveland, $\mathrm{OH}$, and ${ }^{\mathrm{d}}$ University of California, San Francisco, CA, USA
}

\section{Keywords}

Cicatricial alopecia - Erosive pustular dermatosis - Barrier function · Immunosenescence · Hair immunology · Immune dysfunction

\begin{abstract}
Erosive pustular dermatosis (EPD) is a rare condition of the scalp and legs that is marked by crusted erosions or superficial ulcerations that may result in scarring alopecia and chronic wounds. The condition predominantly affects elderly female as compared to male patients. Its pathogenesis remains poorly understood. The majority of the cases in the literature are from the United Kingdom and continental Europe. In this series, we present 8 North American patients with EPD of the scalp, one of whom also had involvement of the legs and another with the involvement of the face. All our patients were advanced in age and had a predisposition to chronic actinic damage, which are common characteristics of EPD previously reported in the literature. We hypothesize that immunosenescence leads to an aberrant immune response to wound healing and, along with other factors such
\end{abstract}

\section{KARGER}

(c) 2017 S. Karger AG, Basel

E-Mail karger@karger.com

www.karger.com/sad as a loss of the normal epidermal barrier, ultraviolet damage, and hormonal factors, may contribute to the development of this condition.

(c) 2017 S. Karger AG, Basel

\section{Introduction}

Erosive pustular dermatosis (EPD) is a rare, but likely underreported condition with a predilection for the chronically sun-damaged scalp and, less commonly, the extremities, particularly the lower legs. There are also isolated reports of the condition presenting on the face [1] and mucosa [2].

EPD was first described by Burton in 1977 [3] and then by Pye et al. in 1979 [4]. The exact cause of the disease is still not fully understood. The characteristic finding of the disease is the development of sterile pustules and chronic crusted erosions. There is often seropurulent material underlying the crusted plaque. This condition has a slowly progressive and sometimes relapsing course. When eventual healing does occur, there is typically residual scarring 
Table 1. Patient characteristics and potential trigger

\begin{tabular}{|c|c|c|c|c|c|c|}
\hline $\begin{array}{l}\text { Age, } \\
\text { years }\end{array}$ & Sex & Race & Potential trigger & $\begin{array}{l}\text { Location } \\
\text { of lesions }\end{array}$ & Microbiology & Treatment \\
\hline 94 & $\mathrm{~F}$ & $\mathrm{C}$ & AK used imiquimod & Scalp & $\begin{array}{l}\text { Heavy growth Staphylococcus } \\
\text { aureus }\end{array}$ & Triamcinolone, mupirocin, cephalexin \\
\hline 89 & $\mathrm{~F}$ & $\mathrm{C}$ & SCC of scalp & Scalp, leg & $\begin{array}{l}\text { Heavy growth Staphylococcus } \\
\text { species }\end{array}$ & Clobetasol, doxycycline, mupirocin \\
\hline 82 & $\mathrm{~F}$ & $\mathrm{C}$ & SCC and KA & Scalp & $\begin{array}{l}\text { Heavy growth Staphylococcus } \\
\text { aureus }\end{array}$ & $\begin{array}{l}\text { Cephalexin, mupirocin, minocycline, } \\
\text { dicloxacillin, fluocinonide }\end{array}$ \\
\hline 82 & $\mathrm{~F}$ & $\mathrm{C}$ & $\mathrm{BCC}$ & Scalp & $\begin{array}{l}\text { Heavy growth Staphylococcus } \\
\text { aureus }\end{array}$ & $\begin{array}{l}\text { Tacrolimus, mupirocin, topical dapsone, } \\
\text { clobetasol, intralesional kenalog, minocycline, } \\
\text { cephalexin }\end{array}$ \\
\hline 70 & $\mathrm{~F}$ & $\mathrm{C}$ & SCC in situ and SCC & Scalp & Mixed flora & Topical clindamycin, clobetasol \\
\hline 87 & $\mathrm{~F}$ & $\mathrm{C}$ & Mohs for SCC & Scalp & No growth & Clobetasol \\
\hline
\end{tabular}

alopecia in affected areas of the scalp, or scarring with post-inflammatory hyperpigmentation on the legs $[1,5]$. Triggering factors include various forms of damage to $\mathrm{cu}-$ taneous integrity including physical and topical therapy, surgery, malignancy, and trauma [5-11]. Acute pustulosis of the scalp is a newer variant of the disease that has been recently described [12].

\section{Patients}

Our patient population consisted of 6 females and 2 males, all of Caucasian background. The mean age of the patients was 84 years, with the youngest patient being 70 years old and the oldest 94 years old. They were followed at a single hair disorders referral center at Kaiser Permanente Northern California. All of our EPD patients had a history of non-melanoma skin cancer or premalignant condition associated with chronic sun damage (Table 1). The skin of the scalp was almost uniformly atrophic. Suspected triggers varied amongst our patients. Our oldest patient of 94 developed crusted eroded lesions at the site of fluorouracil cream field treatment for a cluster of actinic keratosis of the scalp. Four of the patients were known for squamous cell carcinoma. One patient also had involvement of the anterior tibia region and another patient had involvement of the face. The clinical presentation was varied from scale crust to exudative ulcers with sterile pustules
(Fig. 1a-c). All patients had a bacterial and fungal culture as well as a punch biopsy performed. Fungal cultures were negative in all patients. A majority of patients had infection with Staphylococcus species.

Histological examination in all cases showed a mixed dense dermal infiltrate consisting of lymphocytes, neutrophils, and plasma cells overlying an atrophic or eroded epidermis with hyperkeratosis and parakeratosis. Chronic sun damage of the patients' skin was clearly evident with the presence of solar elastosis (Fig. 1d).

Treatments included manual debridement of the crust as well as use of high-potency topical corticosteroids, intralesional corticosteroids, topical tacrolimus, topical dapsone, and topical and oral antibiotics. A summary of patient characteristics and treatments is listed in Table 1.

\section{Discussion}

\section{Diagnosis of Exclusion}

Diagnosis of EPD requires a high clinical suspicion in the appropriate clinical context and is a diagnosis of exclusion with the differential diagnoses including primary cutaneous bacterial and fungal infection and superinfection of a preexisting dermatological condition with causative agents such as S. aureus, S. epidedermidis, Pseudo- 
Fig. 1. Morphological and histological presentation of Erosive Pustular Dermatosis. a Draining pustules, dry crusting and erosion. b Hemorrhagic crust with surrounding erythema and hypopigmentation on right lower cheek. c Dry serous crusting with light erythema on areas of scarring alopecia. d Histological findings include epidermal atrophy, acantholysis, and focal erosion with dense mixed inflammatory infiltrate. e Well-demarcated erythematous plaque with superficial erosion on the right lower leg.
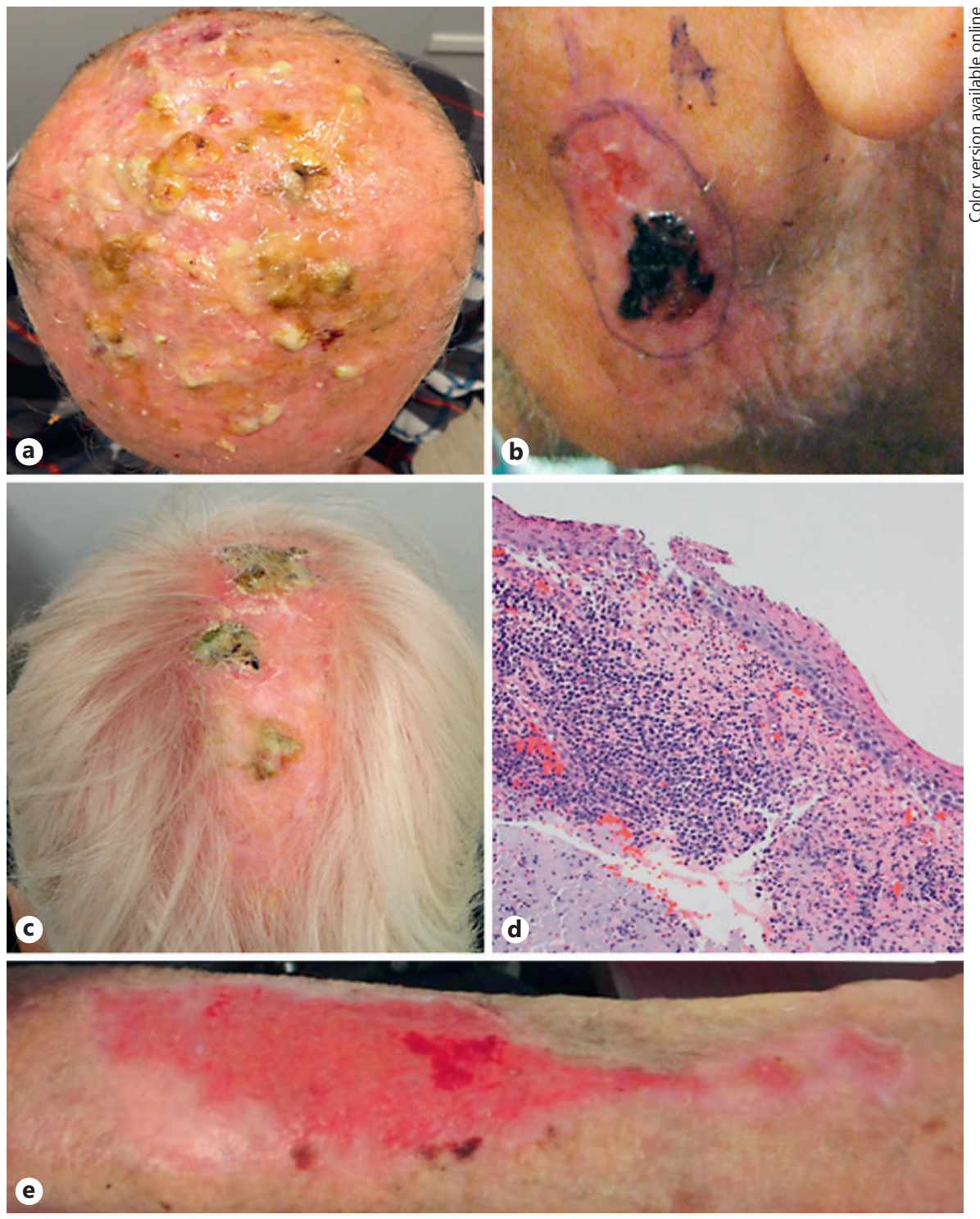

monas spp., human herpes virus, Candida albicans, and Aspergillus ochraceus. Noninfectious entities to consider in the differential include autoimmune blistering disorders (pemphigus vulgaris, pemphigus foliaceous, and cicatricial pemphigoid) and atrophic lichen planus, pyoderma gangrenosum, and malignancy such as squamous cell carcinoma. Pathology showing a mixed dense inflammatory infiltrate and coexisting actinic damage is supportive of the diagnosis of EPD.

\section{Immune and Barrier Dysfunction}

The immune system is thought to decline in fidelity and efficiency with age, resulting in an increased suscep- tibility to infectious diseases and pathological conditions relating to inflammation or autoreactivity. This overall change in immunity is termed "immunosenescence." The process in the elderly is thought to be the opposite of what happens after birth where the inborn or innate immune response is gradually complemented by the learned adaptive immunity. With immunosenescence, the immune system becomes less able to respond to foreign antigens and maintain tolerance to self [13-17]. The term "inflamm-aging" has been coined to describe the phenomenon of chronic low-level innate immune activation leading to increased oxidative stress. Reactive oxygen species are believed to be the driving force in the pathogenesis of 
most if not all major diseases of non-resolving inflammation [18] and are also associated with immunosenescence [19].

The aging immune system is known to have less tolerance to self and an increased rate of autoreactivity. Hair follicles with their characteristic low-surface major histocompatibility complex (MHC) are classified as an immune privilege site, a title mainly attributed to several vital organs including the brain, testes, and cornea [20]. EPD may have an association with other autoimmune diseases $[1,21]$. Recently, regulatory T cells (Treg), important for immune homeostasis, have been shown to preferentially localize to hair follicles [22, 23]. Interestingly, the Treg in association with hair follicles play an important role in establishing immune tolerance to commensal bacteria during the neonatal period [24]. Whether this critical function of Tregs and their ability to control unnecessary immune reactions is maintained later on in life is yet to be determined. Furthermore, complicating our understanding is the variation that exists in the microbiome population of elderly versus young individuals [25].

The barrier function of the skin decreases with age, as the result of age-related epidermal atrophy, elastolysis, and reduced collagen biosynthesis as well as increased collagen fibril fragmentation and degradation [26]. Alteration of skin architecture and epidermal barrier defects result in an increased susceptibility to cutaneous infections and deeper bacterial penetration of the epidermis $[27,28]$.

Given the clinical and pathologic features of EPD [29], signified by an aberrant inflammatory response to wound healing, chronic inflammation, and a predilection to infection in the elderly, it is intriguing to consider whether this condition is a manifestation of immunosenescence. Chemotherapeutic drugs known to lower the host immune function have also been shown to be associated with the development of EPD [30]. Interestingly, on the other end of the spectrum, EPD has been reported to occur in neonates who have incurred trauma to the scalp [31].

Other inflammatory cutaneous conditions that have been proposed to be manifestations of immunosenescence include pruritic papules of the elderly, prurigo nodularis, and Grover's disease [32]. The pro-inflammatory effects of innate immune cells have also been implicated in bullous pemphigoid, another condition seen almost exclusively in the elderly [33].

\section{Ultraviolet Exposure}

One of the hallmarks of EPD is chronic actinic damage. Oxidative stress on the epidermal keratinocytes and fibroblasts cells may have a contributory role in the development of EPD.

A possible explanation for the development of EPD is that chronic ultraviolet exposure leads to the modification of intracellular components. These modified factors are kept hidden internally until cell damage in the form of malignancy, trauma, etc. occurs. In genetically susceptible individuals, these factors, once released into their environment, activate the innate and adaptive immune systems. The age-related over-activation of the innate immune system described above, combined with the inability to properly heal wounds, may contribute to the chronic presentation of EPD. That the driving force of the disease is the exaggerated immune response is evidenced by a recent report of concomitant elevation of serum matrix metalloproteinase-3 in patients with EPD [34] and multiple cases that have been successfully treated with immunosuppressive therapies [2, 35-37]. Amplification of the immune reaction can also be triggered by topical treatments used in dermatology including imiquimod, 5-fluorouracil, and ingenol mebutate, which have been reported to cause EPD in chronically sun-damaged patients [8, $38,39]$.

\section{Hormonal Influence}

As the majority of the affected patient population consists of postmenopausal women, the hormonal state of the patient may play a role in the pathogenesis of the disease. It is well known that, following menopause, the skin becomes thinner and exogenous estrogen therapy can reverse the process by increasing dermal collagen content [40-43]. The need for optimal gonadal steroid hormones for proper wound healing has been described in both human and mouse models [44-47]. Zhou et al. [48] have recently shown that female mice without ovaries had delayed cutaneous wound healing, with a thinner epidermis and fewer proliferating keratinocytes in the wound bed. Ashcroft and colleagues $[49,50]$ demonstrated that intrinsic aging is associated with excessive inflammation and protease activity [49] and topical estrogen can accelerate wound healing by reestablishing a proper immune response in elderly patients [50]. Ample evidence exists regarding the role of estrogen in protecting against oxidative stress [51-52].

\section{EPD of the Leg and Venous Stasis}

EPD of the leg is an under-recognized condition with nonspecific clinical and histological features. Most of the cases in the literature are associated with chronic venous insufficiency. Whether the venous insufficiency contrib- 
utes to its development or is a coincidental finding is still not known. Stasis dermatitis secondary to chronic venous insufficiency is a common condition while EPD of the leg is rare even amongst these patients. Brouard et al. [53] reported that less than $0.5 \%$ of patients presenting to their leg ulcer clinics developed EPD of the leg. There are also reports of EPD of the leg presenting in the absence of stasis dermatitis [54]. We believe that, although the poor circulatory status in patients with venous stasis may impair the proper healing of EPD of the leg, the two entities have a divergent pathophysiology. These patients share an elderly age and long history of sun exposure as well as previous trauma in the site of EPD development, which are most likely the primary contributing factors in development of EPD of the leg.

\section{Treatment}

Treatments described in the literature and used in our patients address the underlying pathophysiology of immune dysregulation associated with poor wound healing in EPD. The mainstay of treatment is immunosuppression with topical superpotent corticosteroids or systemic prednisone. Other topical regimens that have been successfully used include topical calcineurin inhibitors [36, 55, 56]. Topical [57] and systemic dapsone [2] have also been used to address the abnormally exaggerated immune reaction in these patients. Retinoids, which suppress the immune system by normalizing the Toll-like receptor 2-mediated immune response, have also been effective in some cases $[58,59]$. Retinoids also have the added benefit of reestablishing the collagen content in the dermis and thus promoting proper wound healing [60, $61]$. EPD patients may also benefit from topical and sys- temic estrogen therapy. As discussed above, estrogen has the benefit of increasing skin collagen content, thickness, elasticity, and hydration, which improves the rate of wound healing in postmenopausal women [50, 62]. Photodynamic therapy (PDT) has both been shown to trigger and treat EPD [63, 64]. A case series using aminolevulinic acid PDT was successful in treating 8 patients [65]. The authors of the study concluded that PDT with methyl aminolevulinate should be avoided because its increased lipophilic property and longer incubation period may have contributed to toxicity in their patients, thus triggering EPD.

\section{Conclusion}

As described in our series and in others, EPD may be a manifestation of immunosenescence in concert with other contributing factors such as loss of normal epidermal barrier, ultraviolet damage, and hormonal factors. A better understanding of the pathophysiology of EPD will help address this complex condition in the elderly and enable strategies for prevention, early recognition, and improved treatment.

\section{Statement of Ethics}

All subjects have given their informed consent and the study protocol was approved by the Kaiser Permanente Vallejo medical ethics committee.

\section{Disclosure Statement}

The authors have no conflicts of interest to disclose.

\section{References}

1 Van Exel CE, English JC, 3rd: Erosive pustular dermatosis of the scalp and nonscalp. J Am Acad Dermatol 2007;57(2 suppl):S11-S14

2 Feramisco JD, Goerge T, Schulz SE, Ma HL, Metze D, Steinhoff M: Disseminated erosive pustular dermatosis also involving the mucosa: successful treatment with oral dapsone. Acta Derm Venereol 2012;92:91-92.

3 Burton JL: Case for diagnosis. Pustular dermatosis of scalp. Br J Dermatol 1977;97(suppl 15):67-69.

4 Pye RJ, Peachey RD, Burton JL: Erosive pustular dermatosis of the scalp. Br J Dermatol 1979;100:559-566.
5 Grattan CE, Peachey RD, Boon A: Evidence for a role of local trauma in the pathogenesis of erosive pustular dermatosis of the scalp. Clin Exp Dermatol 1988;13:7-10.

6 Rongioletti F, Delmonte S, Rossi ME, Strani GF, Rebora A: Erosive pustular dermatosis of the scalp following cryotherapy and topical tretinoin for actinic keratoses. Clin Exp Dermatol 1999;24:499-500.
7 Marzano AV, Ghislanzoni M, Zaghis A, Spinelli D, Crosti C: Localized erosive pustular dermatosis of the scalp at the site of a cochlear implant: successful treatment with topical tacrolimus. Clin Exp Dermatol 2009;34:e157e159.

8 Vaccaro M, Barbuzza O, Guarneri B: Erosive pustular dermatosis of the scalp following treatment with topical imiquimod for actinic keratosis. Arch Dermatol 2009;145:13401341. 
9 Toda N, Fujimoto N, Kato T, et al: Erosive pustular dermatosis of the scalp-like eruption due to gefitinib: case report and review of the literature of alopecia associated with EGFR inhibitors. Dermatology 2012;225:18-21.

10 Yu X, Liu Y, Ozukum M, Song Z: Erosive pustular dermatosis of the scalp associated with myelodysplastic syndrome. J Eur Acad Dermatol Venereol 2016;30:380-381.

11 Rongioletti F, Chinazzo C, Javor S: Erosive pustular dermatosis of the scalp induced by ingenol mebutate. J Eur Acad Dermatol Venereol 2016;30:e110-e111.

12 Aigner B, Legat FJ, Schuster C, El ShabrawiCaelen L: Sun-induced pustular dermatosis of the scalp - a new variant of erosive pustular dermatosis of the scalp? Acta Derm Venereol 2014;94:457-458.

13 Shaw AC, Joshi S, Greenwood H, Panda A, Lord JM: Aging of the innate immune system. Curr Opin Immunol 2010;22:507-513.

14 Linton PJ, Dorshkind K: Age-related changes in lymphocyte development and function. Nat Immunol 2004;5:133-139.

15 Canaday DH, Parker KE, Aung H, Chen HE Nunez-Medina D, Burant CJ: Age-dependent changes in the expression of regulatory cell surface ligands in activated human T-cells. BMC Immunol 2013;14:45.

16 Duggal NA, Upton J, Phillips AC, Sapey E, Lord JM: An age-related numerical and functional deficit in CD19(+) CD24(hi) CD38(hi) $B$ cells is associated with an increase in systemic autoimmunity. Aging Cell 2013;12: 873-881.

17 Hazeldine J, Lord JM: Innate immunesenescence: underlying mechanisms and clinical relevance. Biogerontology 2015;16:187-201.

18 Nathan C, Ding A: Nonresolving inflammation. Cell 2010;140:871-882.

19 Bauer ME, Fuente Mde L: The role of oxidative and inflammatory stress and persistent viral infections in immunosenescence. Mech Ageing Dev 2016;158:27-37.

20 Paus R, Bertolini M: The role of hair follicle immune privilege collapse in alopecia areata: status and perspectives. J Investig Dermatol Symp Proc 2013;16:S25-S27.

21 Starace M, Loi C, Bruni F, et al: Erosive pustular dermatosis of the scalp: clinical, trichoscopic, and histopathologic features of 20 cases. J Am Acad Dermatol 2017;76:1109-1114. e2.

22 Gratz IK, Truong HA, Yang SH, et al: Cutting Edge: memory regulatory T cells require IL-7 and not IL-2 for their maintenance in peripheral tissues. J Immunol 2013;190:4483-4487.

23 Sanchez Rodriguez R, Pauli ML, Neuhaus IM, et al: Memory regulatory $\mathrm{T}$ cells reside in human skin. J Clin Invest 2014;124:1027-1036.

24 Scharschmidt TC, Vasquez KS, Pauli ML, et al: Commensal Microbes and Hair Follicle Morphogenesis Coordinately Drive Treg Migration into Neonatal Skin. Cell Host Microbe 2017;21:467-477.e5.
25 O’Toole PW, Jeffery IB: Gut microbiota and aging. Science 2015;350:1214-1215.

26 Rittie L, Fisher GJ: Natural and sun-induced aging of human skin. Cold Spring Harb Perspect Med 2015;5:a015370.

27 Natsuga K, Cipolat S, Watt FM: Increased Bacterial Load and Expression of Antimicrobial Peptides in Skin of Barrier-Deficient Mice with Reduced Cancer Susceptibility. J Invest Dermatol 2016;136:99-106.

28 Jafferany M, Huynh TV, Silverman MA, Zaidi Z: Geriatric dermatoses: a clinical review of skin diseases in an aging population. Int $\mathrm{J}$ Dermatol 2012;51:509-522.

29 Caruso C, Buffa S, Candore G, et al: Mechanisms of immunosenescence. Immun Ageing 2009;6:10.

30 Black JM, Hodari KT, Rogers N, Farris PK, Lewis AT, Boh EE: Exudative, nonhealing scalp: a complication of systemic chemotherapy with capecitabine and bevacizumab. Arch Dermatol 2011;147:134-135.

31 Siegel DH, Holland K, Phillips RJ, Drolet BA Esterly NB, Frieden IJ: Erosive pustular dermatosis of the scalp after perinatal scalp injury. Pediatr Dermatol 2006;23:533-536.

32 Berger TG, Steinhoff M: Pruritus in elderly patients-eruptions of senescence. Semin $\mathrm{Cu}-$ tan Med Surg 2011;30:113-117.

33 Le Jan S, Plee J, Vallerand D, et al: Innate immune cell-produced IL-17 sustains inflammation in bullous pemphigoid. J Invest Dermatol 2014;134:2908-2917.

34 Aoshima M, Ito T, Tokura Y: Erosive pustular dermatosis of the scalp arising concomitantly with elevation of serum matrix metalloproteinase- 3 in a patient with rheumatoid arthritis. The Journal of dermatology 2015;42:540541.

35 Vassallo C, Derlino F, Brazzelli V, D’Ospina $\mathrm{RD}$, Borroni G: Acute generalized exanthematous pustulosis: report of five cases and systematic review of clinical and histopathological findings. Giornale italiano di dermatologia e venereologia: organo ufficiale, Societa italiana di dermatologia e sifilografia 2014; 149:281-290

36 Zahdi MR, Seidel GB, Soares VC, Freitas CF, Mulinari-Brenner FA: Erosive pustular dermatosis of the scalp successfully treated with oral prednisone and topical tacrolimus. Anais brasileiros de dermatologia 2013;88:796-798.

37 Dall'Olio E, Rosina P, Girolomoni G: Erosive pustular dermatosis of the leg: long-term control with topical tacrolimus. The Australasian journal of dermatology 2011;52:e15-e17.

38 Corradin MT, Forcione M, Giulioni E, Fiorentino R, Ferrazzi A, Alaibac M: Erosive pustular dermatosis of the scalp induced by imiquimod. Case Rep Dermatol Med 2012;2012: 828749 .

39 Rongioletti F, Chinazzo C, Javor S: Erosive pustular dermatosis of the scalp induced by ingenol mebutate. J Eur Acad Dermatol Venereol 2016;30:e110-e111.
40 Punnonen R: Effect of castration and peroral estrogen therapy on the skin. Acta Obstet Gynecol Scand Suppl 1972;21:3-44.

41 Maheux R, Naud F, Rioux M, et al: A randomized, double-blind, placebo-controlled study on the effect of conjugated estrogens on skin thickness. Am J Obstet Gynecol 1994;170: 642-649.

42 Affinito P, Palomba S, Sorrentino C, et al: Effects of postmenopausal hypoestrogenism on skin collagen. Maturitas 1999;33:239-247.

43 Sauerbronn AV, Fonseca AM, Bagnoli VR, Saldiva PH, Pinotti JA: The effects of systemic hormonal replacement therapy on the skin of postmenopausal women. Int J Gynaecol Obstet 2000;68:35-41.

44 Campbell L, Emmerson E, Davies F, et al: Estrogen promotes cutaneous wound healing via estrogen receptor beta independent of its antiinflammatory activities. J Exp Med 2010; 207:1825-1833.

45 Gilliver SC, Ruckshanthi JP, Hardman MJ, Nakayama T, Ashcroft GS: Sex dimorphism in wound healing: the roles of sex steroids and macrophage migration inhibitory factor. Endocrinology 2008;149:5747-5757.

46 Gilliver SC, Ruckshanthi JP, Hardman MJ, Zeef LA, Ashcroft GS: 5alpha-dihydrotestosterone (DHT) retards wound closure by inhibiting re-epithelialization. J Pathol 2009; 217:73-82.

47 Hardman MJ, Ashcroft GS: Estrogen, not intrinsic aging, is the major regulator of delayed human wound healing in the elderly. Genome Biol 2008;9:R80.

48 Zhou T, Yang Z, Chen Y, et al: Estrogen Accelerates Cutaneous Wound Healing by Promoting Proliferation of Epidermal Keratinocytes via Erk/Akt Signaling Pathway. Cell Physiol Biochem 2016;38:959-968.

49 Ashcroft GS, Horan MA, Herrick SE, Tarnuzzer RW, Schultz GS, Ferguson MW: Agerelated differences in the temporal and spatial regulation of matrix metalloproteinases (MMPs) in normal skin and acute cutaneous wounds of healthy humans. Cell Tissue Res 1997;290:581-591.

50 Ashcroft GS, Greenwell-Wild T, Horan MA, Wahl SM, Ferguson MW: Topical estrogen accelerates cutaneous wound healing in aged humans associated with an altered inflammatory response. Am J Pathol 1999;155:11371146.

51 Prokai L, Prokai-Tatrai K, Perjesi P, et al: Quinol-based cyclic antioxidant mechanism in estrogen neuroprotection. Proc Natl Acad Sci USA 2003;100:11741-11746.

52 Chang KC, Wang Y, Oh IG, et al: Estrogen receptor beta is a novel therapeutic target for photoaging. Mol Pharmacol 2010;77:744750.

53 Brouard MC, Prins C, Chavaz P, Saurat JH, Borradori L: Erosive pustular dermatosis of the leg: report of three cases. Br J Dermatol 2002;147:765-769.
Erosive Pustular Dermatosis and Immunosenescence
Skin Appendage Disord 2018;4:180-186 DOI: $10.1159 / 000484488$ 
54 Zhou Z, Zhang ZK, Liu TH: Erosive pustular dermatosis of the leg mimicking lower limb cellulitis. Clin Exp Dermatol 2015;40:865867.

55 Tardio NB, Daly TJ: Erosive pustular dermatosis and associated alopecia successfully treated with topical tacrolimus. J Am Acad Dermatol 2011;65:e93-e94.

56 Laffitte E, Kaya G, Piguet V, Saurat JH: Erosive pustular dermatosis of the scalp: treatment with topical tacrolimus. Arch Dermatol 2003;139:712-714.

57 Broussard KC, Berger TG, Rosenblum M, Murase JE: Erosive pustular dermatosis of the scalp: a review with a focus on dapsone therapy. J Am Acad Dermatol 2012;66:680-686.
58 Petersen BO, Bygum A: Erosive pustular dermatosis of the scalp: a case treated successfully with isotretinoin. Acta Derm Venereol 2008:88:300-301

59 Dispenza MC, Wolpert EB, Gilliland KL, et al: Systemic isotretinoin therapy normalizes exaggerated TLR-2-mediated innate immune responses in acne patients. J Invest Dermatol 2012;132:2198-2205.

60 Bravo BS, Azulay DR, Luiz RR, MandarimDe-Lacerda CA, Cuzzi T, Azulay MM: Oral isotretinoin in photoaging: objective histological evidence of efficacy and durability. Anais brasileiros de dermatologia 2015;90: 479-486.

61 de Campos Peseto D, Carmona EV, Silva KC, et al: Effects of tretinoin on wound healing in aged skin. Wound Repair Regen 2016;24: 411-417.
62 Archer DF: Postmenopausal skin and estrogen. Gynecol Endocrinol 2012;28(suppl 2):26.

63 Guarneri C, Vaccaro M: Erosive pustular dermatosis of the scalp following topical methylaminolaevulinate photodynamic therapy. J Am Acad Dermatol 2009;60:521-522.

64 Lopez V, Lopez I, Ramos V, Ricart JM: Erosive pustular dermatosis of the scalp after photodynamic therapy. Dermatol Online J 2012;18:13.

65 Yang CS, Kuhn H, Cohen LM, Kroumpouzos G: Aminolevulinic Acid Photodynamic Therapy in the Treatment of Erosive Pustular Dermatosis of the Scalp: A Case Series. JAMA Dermatol 2016;152:694-697. 